\title{
Application of Microperforated-Panel Absorber in Communication Products
}

\author{
Wenfang Yu, Xianming Zhang, Qingshan Dong \\ Reliability Department, Wireless Product R \& D Institute, Wireless Product Operation Division, ZTE Corporation, Shenzhen, China \\ Email:yu.wenfang@zte.com.cn
}

How to cite this paper: Yu, W.F., Zhang, X.M. and Dong, Q.S. (2018) Application of Microperforated-Panel Absorber in Communication Products. Journal of Applied Mathematics and Physics, 6, 51-57. https://doi.org/10.4236/jamp.2018.61006

Received: December 7, 2017

Accepted: January 2, 2018

Published: January 5, 2018

\begin{abstract}
Base on Prof. Maa Dah-You's general theory of the microperforated-panel (MPP) absorber, We designed a noise reduction structure-sound attenuating cabinet (SAC). It can be applied to air-cooled communication products to reduce system noise. This article introduces engineering design method of SAC and laboratory test noise reduction results of application of SAC.
\end{abstract}

\section{Keywords}

Microperforated-Panel (MPP), Sound Attenuating Cabinet (SAC), Air-Cooled Communication Products

\section{Introduction}

Since the late 60s of the 20th Prof Maa Dah-You proposed the theory of microperforated-panel (Mpp) absorber [1] [2], MPP absorber has been widely used in acoustics area [3]. Many researchers have done a lot of research on MPP. According to the accurate theory of MPP, the absorption bandwidth may extend to three, four or more octaves. MPP absorber eliminates the porous material. It is a good resonant sound absorber with simple structure and less affected by the wind [4]. So MPP absorber may be widely used in high-speed airflow and high-sounding pipe system. These advantages of MPP absorber make it is possible to be applied for our company's air-cooled communication products [5].

Due to the enhancement of production function, the products heat consumption increases. In order to ensure air-cooled products long-term reliability, temperature should be control within a certain range. The effective method is increase fans volume flow, which may lead to products noise exceeding noise standards. Base on the accurate theory of MPP, We designed a noise reduction structure named Sound attenuating cabinet (SAC). Noise level of air-cooled 
products can be reduced by application of SAC.

This article mainly introduces engineering calculations of SAC and laboratory test noise reduction results of application of SAC.

\section{MPP General Theory and Calculation Equation [1] [6]}

MPP structure parameters:

$d$-Perforation diameter, $\mathrm{mm}$; $t$-Plate thickness, $\mathrm{mm}$; $b$-Hole spacing, $\mathrm{mm}$; $D$-Cavity thickness, $\mathrm{m}$;

$p$-Perforated part of the area and the ratio of the total area (\%); $\rho$-Air density, $\mathrm{kg} / \mathrm{m}^{3} ; c$-Sound velocity, $340 \mathrm{~m} / \mathrm{s}$;

$f$-Sound frequency, $\mathrm{Hz} ; f_{0}$-Resonance frequency, $\mathrm{Hz} ; f_{1}$-Half absorption point frequency(small), Hz;

$f_{2}$-Half absorption point frequency(large), $\mathrm{Hz}$;

Perforate constant

$$
k=0.21 \sqrt{f_{0}}
$$

Relative acoustic resistance $r$, it's the ratio of the acoustic impedance to the air-specific impedance

$$
r=\frac{0.335 t}{p d^{2}} k_{r}, k_{r}=\left(1+\frac{k^{2}}{32}\right)^{1 / 2}+\frac{\sqrt{2}}{8} \frac{k d}{t}
$$

MPP relative sound quality $m$, it's the ratio of sound quality and air resistance

$$
m=\frac{0.294 \times 10^{-3} t}{p} k_{m}, k_{m}=1+\left(9+\frac{k^{2}}{2}\right)^{-1 / 2}+0.85 \frac{d}{t}
$$

The acoustic absorption coefficient $\alpha$ when the acoustic wave enter the MPP:

$$
\alpha=\frac{4 r}{(1+r)^{2}+\left(\omega m-\cot \left(\frac{\omega D}{c}\right)\right)^{2}}
$$

The acoustic absorption coefficient $\alpha$ reaches the maximum value at resonance frequency:

$$
\alpha_{\max }=\frac{4 r}{\left(1+r^{2}\right)}
$$

The resonance frequency $f_{0}$ satisfies the following Equation (6). According to Equation (7), can get the cavity thickness D of MPP:

$$
\begin{aligned}
& \omega_{0} m-\cot \left(\frac{\omega_{0} D}{c}\right)=0 \\
& D=\frac{c}{\omega_{0}} \operatorname{arccot}\left(\omega_{0} m\right)
\end{aligned}
$$

The Relative acoustic resistance $r$ satisfies the following Equation (8), according to Equation (8), can get P of MPP:

$$
\frac{p}{t}=\frac{0.147 k_{r}}{r d^{2}}
$$


For two-layer MPP, the resonant frequency $f_{0}$ is equal to or lower than the value determined by the following equation:

$$
\omega m_{1}-\cot \frac{\omega\left(D_{1}+D_{2}\right)}{c}=0
$$

\section{The Absorption Band Width of MPP}

When the sound absorption coefficient $\alpha$ is half of the maximum value, $f$ satisfies the following Equation (10):

$$
\begin{gathered}
\Delta f / f_{0}=\frac{4 \arctan (1+r)}{\pi} \\
\frac{f_{2}}{f_{1}}=\frac{\pi}{\operatorname{arccot}(1+r)}-1
\end{gathered}
$$

According to Equation (12) may obtain MPP's acoustic octave band:

$$
n=\log _{2}\left(\frac{f_{2}}{f_{1}}\right)
$$

\section{Application of MPP in Air-Cooled Communication Products}

Air-cooled products use small size, high-speed axial fans. The system noise is mainly aerodynamic noise, including rotation noise and eddy noise. Therefore, there are always one or several peaks in the continuous spectrum of broadband. The peaks are generally more than the continuous part of $5-15 \mathrm{~dB}$.

For company's air-cooled products, the system noise spectrum is shown in Figure 1. It is necessary to reduce the noise at $450 \mathrm{~Hz}-1500 \mathrm{~Hz}$ frequency to make sure system noise meet standards. System air duct is from right to left. Due to the limitation of the product application scene, air duct of SAC should to be designed as a curved way. And the MPP is parallel to the air inlet and outlet. Comprehensive application of curved and MPP can better reduce noise level of system.

\section{Engineering Calculation Method}

By analyzing the system noise propagation mode in SAC, instead of normal incident to MPP, the sound wave diffuse incident to MPP. According to introduction of the diffuse incidence, when the sound wave forms an angle $\theta$ with the normal of the perforation board, air vibration can only be along the normal direction since the MPP is "local action" absorber. So the relative acoustic impedance $r+j a m$ will not change along the incident direction. But it is different for the cavity. The sound wave that transmits through the perforation board like the Huygens principle wavelets. These waves together with the original incident wave propagate in the cavity. After wave transmitting to the back wall, it reflects back to the perforated plate. The reflected wave overlaps with the incident wave to form a half standing wave. In the reverberation chamber, coefficient $\alpha$ can be 


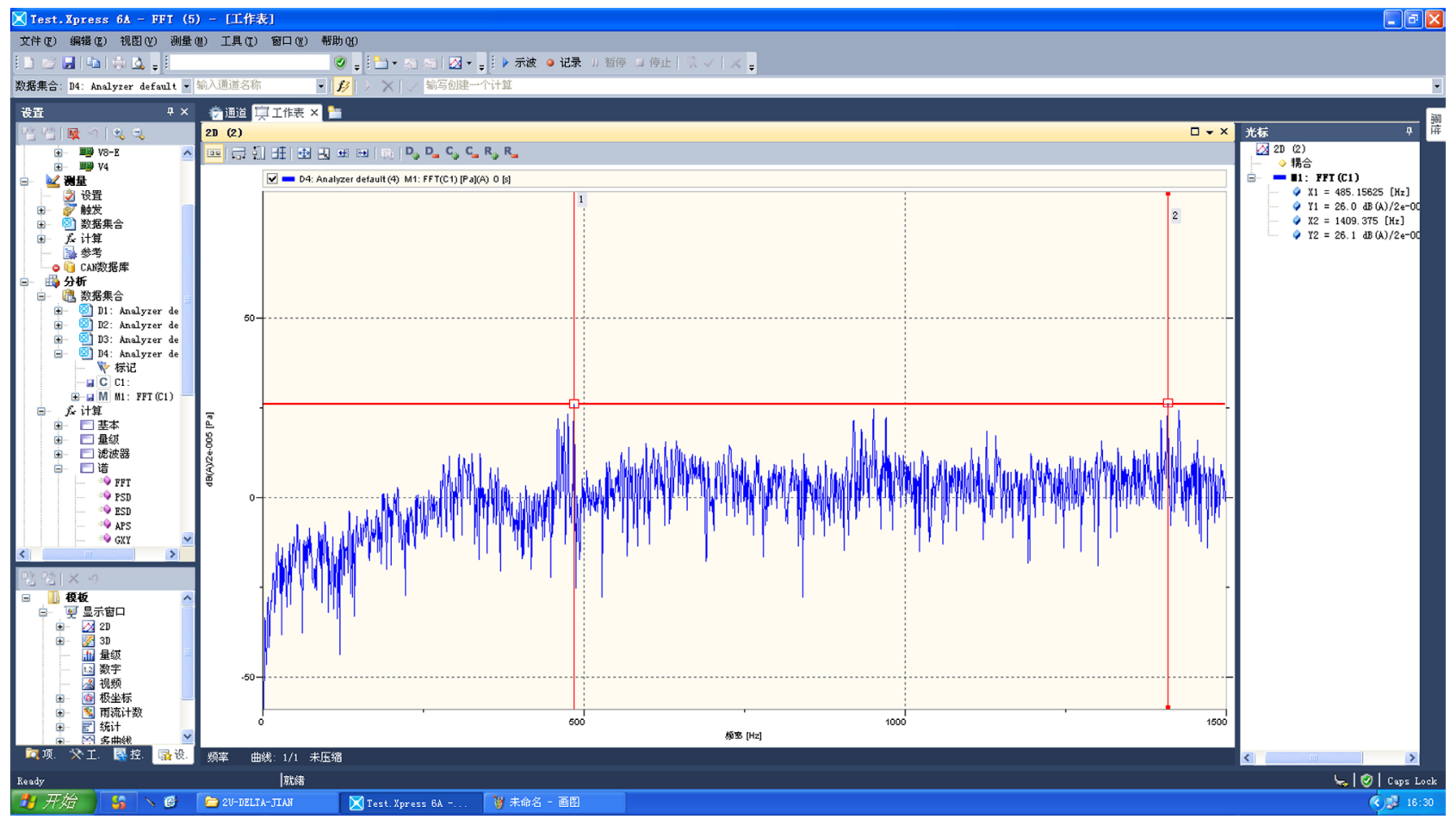

(a)

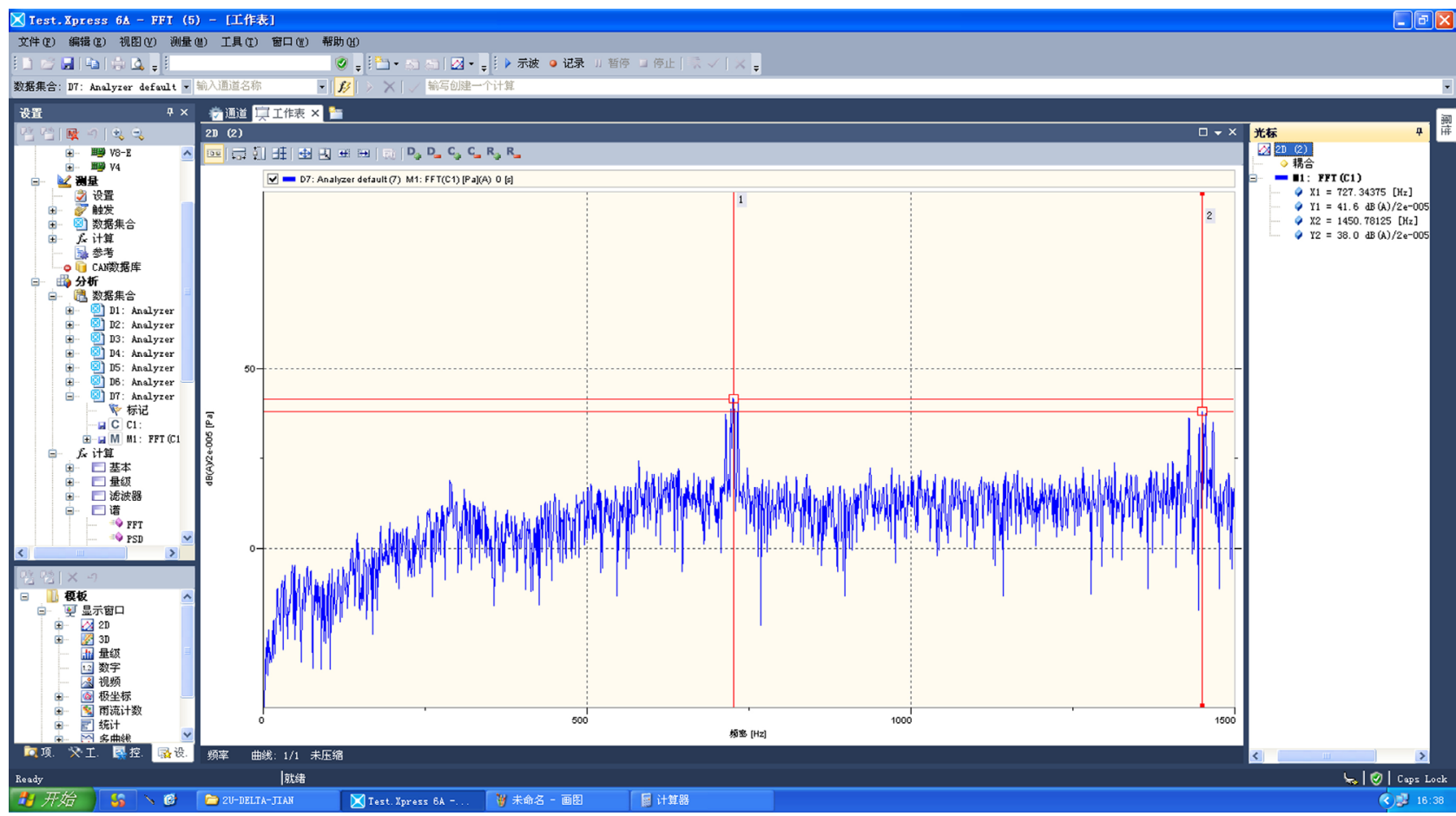

(a)

Figure 1. System spectrum. (a) Work point 1 spectrum. (b) Work point 2 spectrum.

calculated by the Equation (13).

$$
\alpha=\int_{0}^{\pi / 2} \frac{8 r \cos \theta \sin \theta d \theta}{(1+r \cos \theta)^{2}+(2 \pi g y \cos \theta-\cot 2 \pi y \cos \theta)^{2}}
$$


The relative acoustic impedance of the two-layer absorber is approximately equal to value that be calculated Equation (14). The absorption ability of two-layer absorber mainly depends on the function of cavity. Therefore, the microperforated panel of two-layer absorber could be the same structure. It will be easy to produce in engineer.

$$
Z \approx r_{1}\left[1+\frac{D_{2}^{2}}{\left(D_{1}+D_{2}\right)^{2}}\right]+j \omega m_{1}+\frac{1}{j \omega\left(D_{1}+D_{2}\right) / c}
$$

\section{Introduction of SAC}

Figure 2 is the schematic diagram of SAC. SAC is the two-layer microperforated-panel structure. For air-cooled products, long inlet and outlet channel increase air flow resistance. Then products temperature increase. At the same conditions, high products temperature lead to high fans speed. Therefore, after application of SAC, only for air-cooled products, high fans speed lead to product high noise level. So it is necessary to comprehensive evaluate the noise reduction effect of SAC.

The noise test of SAC reference to ISO3744 and is done in the semi-silencer laboratory. Test diagram is shown in Figure 3.

Table 1 shows the noise test results before and after application of SAC by an air-cooled communication product. It shows that product's noise can be effectively reduced by the application of SAC and reach the desired design goals. Especially, at ambient temperature of $35 \& 65^{\circ} \mathrm{C}$, product's fans speed don't change

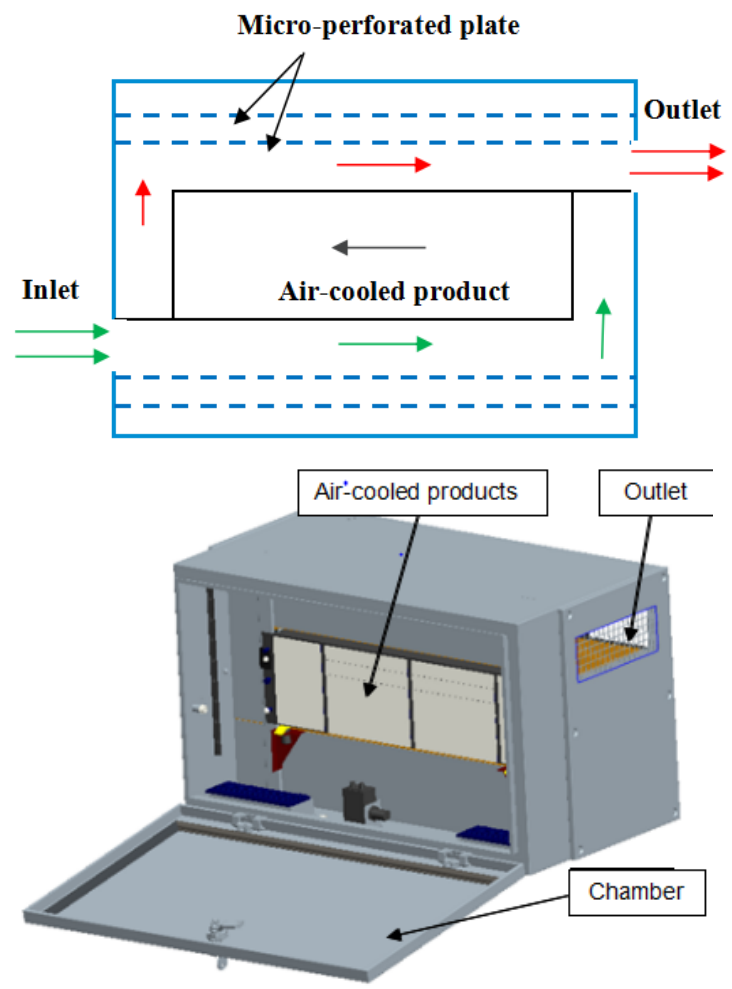

Figure 2. SAC schematic diagram. 
by application of SAC. The reduction of product's noise is more than 8dBA. Furthermore, SAC is suitable for the serious application scenarios. It can improve user experience and enhance the comprehensive competitiveness of outfield products.

\section{Conclusion}

SAC applies the general theory of MPP to communication products. It uses the

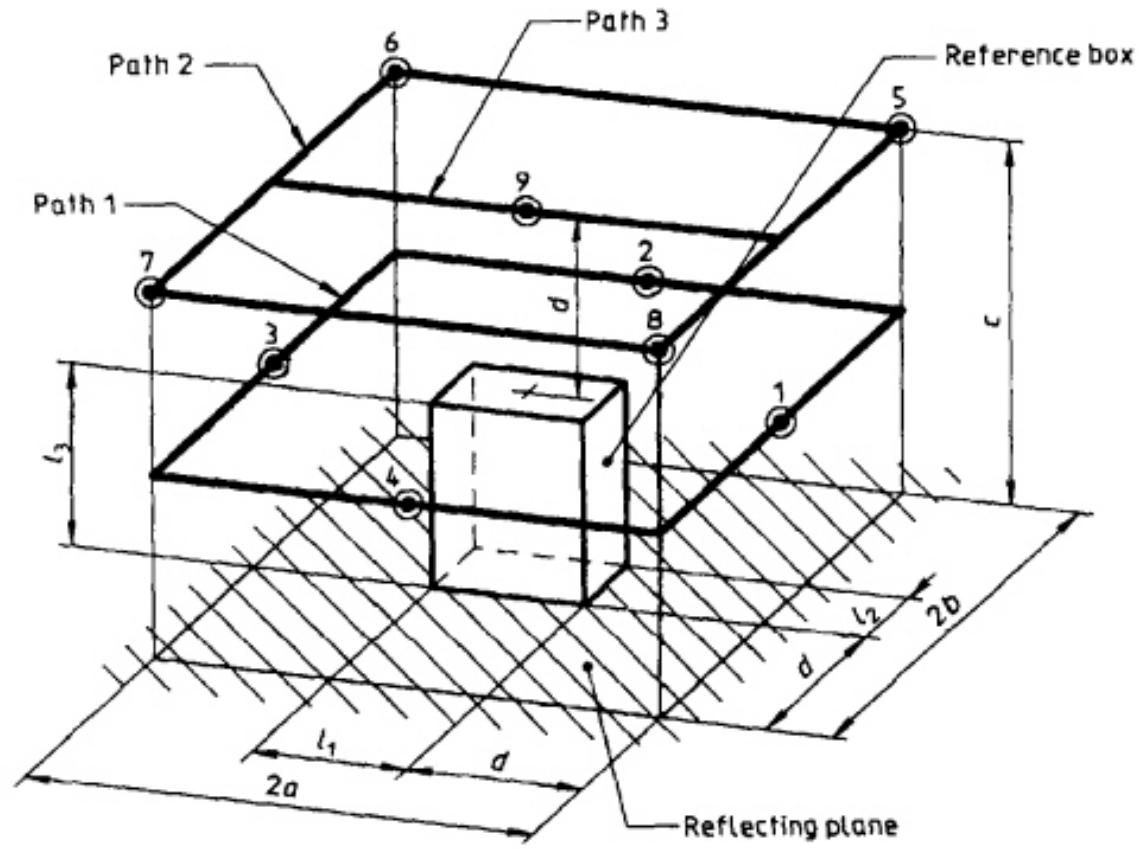

(a)

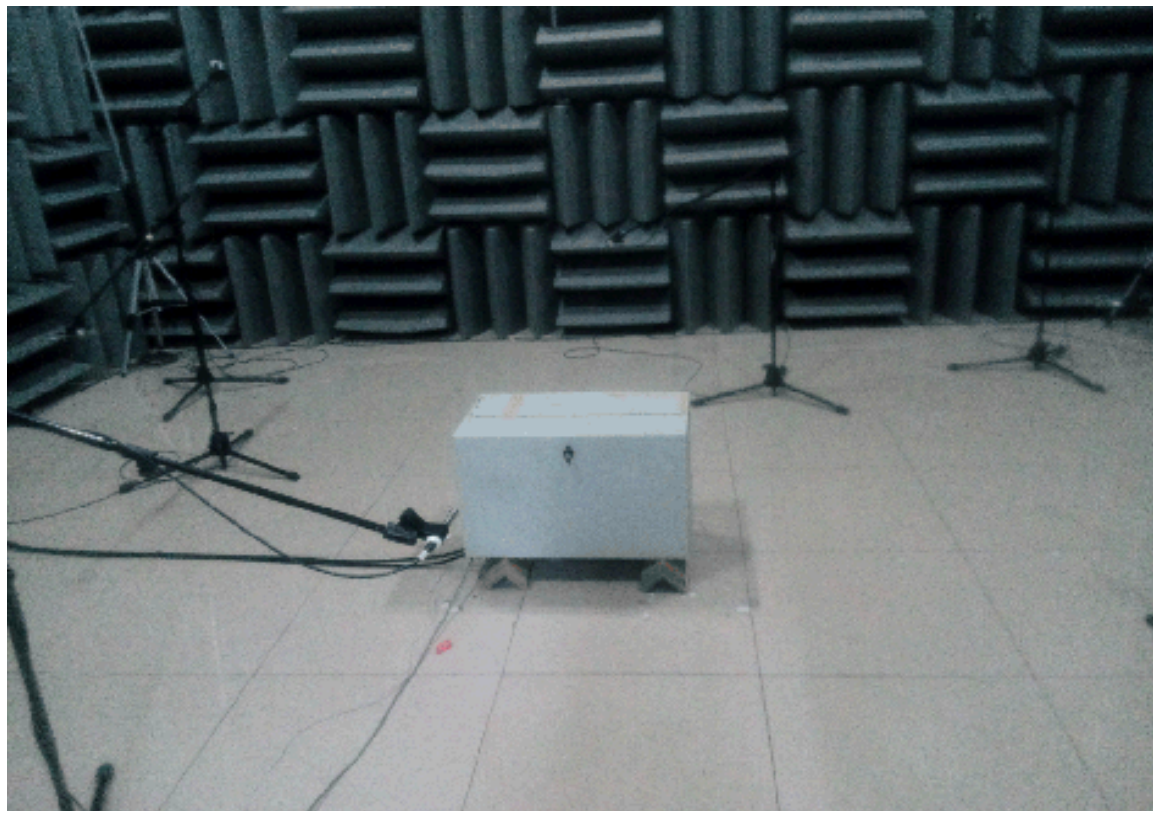

(b)

Figure 3. Test images. 
Table 1. Measured results of SAC.

\begin{tabular}{|c|c|c|c|c|c|c|c|c|}
\hline \multirow{2}{*}{ Test Items } & \multicolumn{2}{|c|}{$\begin{array}{l}\text { Ambient temp. } \\
25^{\circ} \mathrm{C}\end{array}$} & \multicolumn{2}{|c|}{$\begin{array}{c}\text { Ambient temp. } \\
30^{\circ} \mathrm{C}\end{array}$} & \multicolumn{2}{|c|}{$\begin{array}{c}\text { Ambient temp. } \\
35^{\circ} \mathrm{C}\end{array}$} & \multicolumn{2}{|c|}{$\begin{array}{c}\text { Ambient temp. } \\
65^{\circ} \mathrm{C}\end{array}$} \\
\hline & $\begin{array}{l}\text { Only } \\
\text { product }\end{array}$ & In SAC & $\begin{array}{l}\text { Only } \\
\text { product }\end{array}$ & In SAC & $\begin{array}{l}\text { Only } \\
\text { product }\end{array}$ & In SAC & $\begin{array}{l}\text { Only } \\
\text { product }\end{array}$ & In SAC \\
\hline Fan Speed/RPM & 8730 & 9700 & 9700 & 10,700 & 12,000 & 12,000 & 21,900 & 21,900 \\
\hline $\begin{array}{l}\text { Estimated declared } \\
\text { sound power } \\
\text { value/dBA }\end{array}$ & 64.7 & 59.5 & 66.9 & 60.5 & 71.4 & 63.1 & 80.8 & 72.7 \\
\hline $\begin{array}{l}\text { Applied SAC } \\
\text { optimization } \\
\text { value/dBA }\end{array}$ & \multicolumn{2}{|c|}{5.2} & \multicolumn{2}{|c|}{6.4} & \multicolumn{2}{|c|}{8.3} & \multicolumn{2}{|c|}{8.1} \\
\hline
\end{tabular}

aluminum microperforated plate. Metal material plate has the characteristics of temperature resistance and corrosion resistance. Taking into account the working principle of MPP, there will be no clogging of micro-pores. So SAC may is suitable for the field of $\mathrm{PH}$, dust, flumes and other harsh scenes. The noise value of air-cooled products can be reduced about $5.2-8.3 \mathrm{dBA}$ by the application of SAC. It has been proved that Microperforated-panel absorber can effectively reduce noise of communication products.

\section{References}

[1] Dah-You, M.A.A. (1975) The Theory and Design of Microperforated-Panel Absorber. Scientia Sinica.

[2] Dah-You, M.A.A. (1998) Potential of Microperforated Panel Absorber. J. Acoust. Soe. Am, 104, 2861-2866. https://doi.org/10.1121/1.423870

[3] Yu, W.Z. and Wang, Z.M. Design and Test of a New Type of Efficient Natural Ventilation Sound Insulation Window.

[4] Dah-You, M.A.A. (1987) Potential of Microperforated-Panel Wideband Absorbers. Noise Control. Eng. Journ, 29, 77-84. https://doi.org/10.3397/1.2827694

[5] Dah-You, M.A.A. and Liu, K. (2000) Sound Absorption Characteristics of Microperforated Absorber for Random Incidence. Acta Acustica, 25, No. 4.

[6] Jiao, F.L., Liu, K. and Ding, H. (2001) Discussions on the Utmost Frequency Band of a Microperforated-Panel Absorber. Journal of Applied Acoustics, 20, No. 6. 